\title{
Arterial Ischemic Stroke as a First Manifestation of Trousseau's Syndrome
}

\author{
Mustafa Gokce*, Elif Muruvet Benli, Aytac Dinc
}

Neurology Department, Medical Faculty, Kahramanmaras Sutcu Imam University, Kahramanmaras, Turkey.

Email: *hmgokce@hotmail.com

Received October $20^{\text {th }}, 2011$; revised November $19^{\text {th }}, 2011$; accepted December $28^{\text {th }}, 2011$

\begin{abstract}
Malignancy related hypercoagulobility can manifest as acute arterial infarction, non-bacterial thrombotic endocarditis and thrombophlebitis. Rarely, ischemic stroke may be first symptom for a systemic occult cancer. We presented 62-year-old man who had recurrent stroke as the initial manifestation of an occult neoplastic process. Subsequently, the patient had venous thrombotic disease that led to the diagnosis of the malignancy. Conclusions: Acute or sub-acute multiple ischemic stroke may be the first manifestation of in an occult cancer.
\end{abstract}

Keywords: Malignancy; Paraneoplastic Stroke; Occult Cancer; Hypercoagulobility; Ischemic Stroke

\section{Introduction}

Relationship between malignancy and hypercoagulopathy has been known since Armand Trousseau's first description in that a case with migratory thrombophlebitis in the setting of a gastric carsinoma in 1865. The hypercoagulopathy most likely manifest as venous and, rarely, arterial thromboembolic disorders are still among the most common complications of cancer, and are a cause of substantial morbidity and mortality in these patients $[1,2]$. Trousseau's syndrome (TS) is partly the consequence of multiple pathophysiologic mechanisms that apparently contribute to the hypercoagulability associated with cancer [3]. Presentation with ischemic stroke as a first symptom of hypercoagulopaty is very rare therefore may be overlooked as a possible cause of acute ischemic stroke. This report presented one patient who suffering acute arterial ischemic stroke as the first manifestation of an occult malignancy.

\section{Case Report}

A 62-year-old male patient was admitted to our hospital with difficulties of speech, standing and walking during last 6 days. There was no history of hypertension, diabetes mellitus, hyperlipidemia and atherosclerosis. He was a nonsmoker and nondrinker. His physical examination revealed normal status of generally appearance, body temperature, blood pressure etc. He had partially motor dysphasia and mild right hemiparesis, otherwise his neurological examination were unremarkable.

*Corresponding author.
Results of his laboratory results of hemograms, routine biochemistry including liver and kidney and thyroid function tests were all in normal range. ESR $=43 \mathrm{~mm} / \mathrm{h}$ and CRP $=36.4$ levels were high. The prothrombin time (PT) was 17.0 seconds, international neutralization ratio $($ INR) $=1.20$, activated partial prothrombin time (APTT) was 30.1 seconds. Brain computed tomography (CT) scan and magnetic resonance imaging (MRI) revealed multiregional acute, subacute and chronic ischemic lesions on cerebral and cerebellar locations of both hemispheres (Figure 1). Stenosis or occlusion in major neck and brain arteries were not observed on his brain and cervical MRAs. Results of examinations of carotid duplex ultrasonography and transcranial Doppler were unremarkable. No cardiac thrombi were seen in his transthoracic and transeusofagial echocardiography. Right to left cardiac shunt were not determined with Bubble study.

Because of the patient has multiple infarctions in different ages without obvious risk factors for stroke, we investigated all vasculitic and infections markers, Anticardiolipin IgM $=3.9(0-12 \mathrm{U} / \mathrm{mL}), \operatorname{IgG}=5.8(0-12$ $\mathrm{U} / \mathrm{mL}), \mathrm{ANA}=0.48(0-1 \mathrm{U} / \mathrm{ml}), \mathrm{P}-\mathrm{ANCA}=3.2(0-12$ $\mathrm{U} / \mathrm{ml}), \mathrm{C}-\mathrm{ANCA}=9.5(0-12 \mathrm{U} / \mathrm{ml})$ were normal. Brucella agglutination, Salmonella grubel vidal, VDRL-RPR were all negative. Results of subsequent hematologic tests, including protein $\mathrm{C}$, protein $\mathrm{S}$, and anti-thrombin III were normal. Only his homosistein level was $26 \mathrm{U} / \mathrm{L}$ (normal range $=5-12$ ).

While the patient was being discharged without obvious cause of the ischemic stroke he complained a pain on his left side arm and leg. The patient was consulted car- 
diovascular surgery department and subsequent performing ultrasonography was revealed venous thrombosis in left cephalic vein and vena saphena magna. Multiple arterial and venous clots made us thinking possibility a hypercoagulopathy status due to an occult cancer. Further tumor marker studies showed levels of CEA $=112$ (1.1 - $3.4 \mathrm{ng} / \mathrm{mL})$, CA $19-9>1000 \mathrm{U} / \mathrm{ml},(0-33 \mathrm{U} / \mathrm{ml})$ and CA $15.3=51.1 \mathrm{U} / \mathrm{ml},(6.4-38.4 \mathrm{U} / \mathrm{ml}), \mathrm{PSA}=4.11$ $\mathrm{ng} / \mathrm{mL}(0.04-4 \mathrm{ng} / \mathrm{mL})$, AFP $=2.26(0.5-5.5 \mathrm{IU} / \mathrm{mL})$. Because tumor marker studies revealed elevated levels of CA 19 - 9, CEA and CA 15 - 3, a paraneoplastic process-related chronic DIC status was highly suspected and abdominal ultrasound and CT scan of abdominal and thorax investigations were performed. The abdominal and thorax CT revealed indicating thromboembolic lesions an infarct in spleen and multiple lesions consistent with metastases on the liver and pleural involvement (Figure 2).

According to patient's preference, the patient was referred to gastroenterology and general surgery department of an another hospital, subsequently pathological examination of liver biopsy in there revealed multiple liver metastasis of adenocarcinoma unknown origin. Rectoscopy and gastro-endoscopy was unremarkable in there again. Pancreas biopsy was refused by the patient and his family. He finally died due to multiple organ dysfunctions at 3 months after first stroke symptoms.

\section{Discussion}

Our patient had been diagnosed an adenocancer's metastasis on liver unknown origin. Although no tumor was seen on his gastro-endoscopy and rectoscopy examinations, the pathologist thought its origin most likely gastrointestinal tract. Although he and his family refused a pancreas biopsy, a tumor infiltration was seen on his pancreas (Figure 2(b)). We also thought, as his clinician, he most likely had adenocarcinoma of the pancreas.

The French physician Trousseau in 1865 was the first to recognize the association of malignancy and spontaneous venous thrombosis. Most cases of TS occur in persons over 50-years old. Malignancies of the pancreas, lung and intestinal tract have been most commonly associated with TS, but it has been observed with essentially

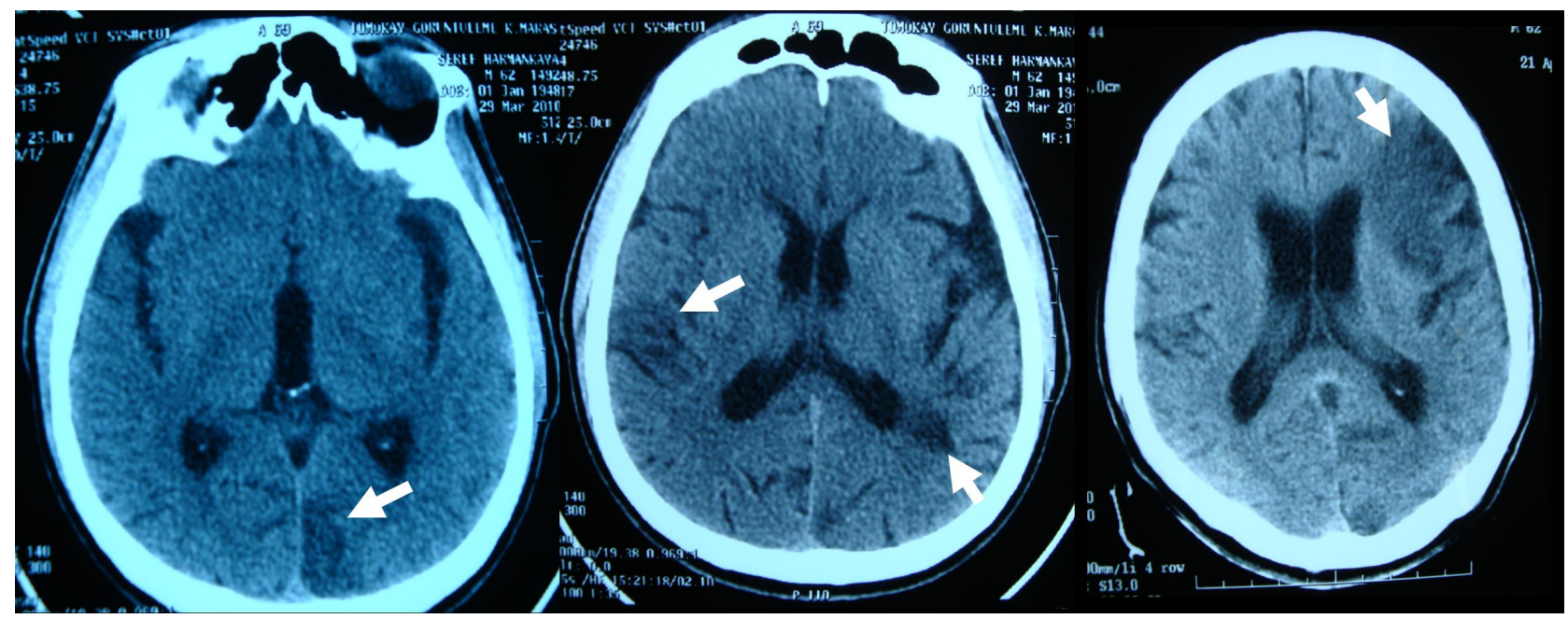

Figure 1. Multiple infarctions are seen patient's head CT (these CT sections were obtained in different times).

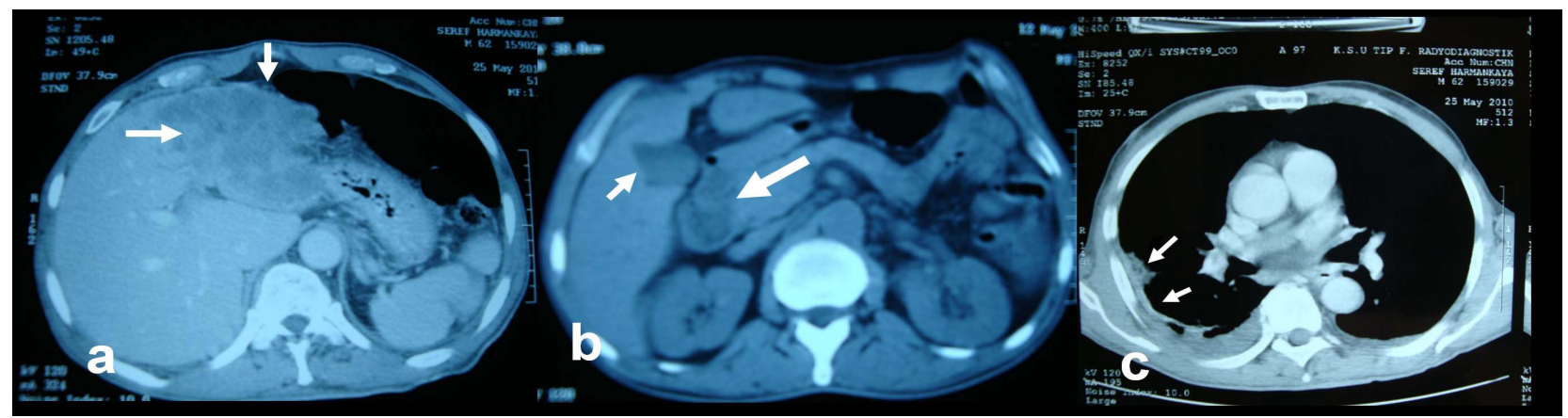

Figure 2. Heterogeneous hypointensity in left side of liver (small arrows in Figure 2(a)) and part of the pancreas (large arrow in Figure 2(b)) on abdominal MRI. In addition right pleural thickening and a soft tissue extending inside to the right lung on thorax CT (arrows in Figure 2(c)) are seen. 
all cancers [1,2]. TS can present as an acute arterial thrombosis, non-bacterial thrombotic endocarditis, or migratory thrombophlebitis. In advanced cancer, a prothrombotic or hypercoagulable state is a frequent complication and may be encountered as an asymptomatic abnormal coagulation test or as a massive clinical thromboembolism [4]. In general, thromboembolic disease in patients with cancer does not differ clinically from that in other types of patients. Indeed, deep-venous thrombosis (DVT) of the leg is the most common clinical manifestation of thromboembolic disease in cancer patients, although arm DVT, pulmonary embolism, cerebral sinus thrombosis, migratory superficial thrombophlebitis, DIC, and thrombotic microangiopathy have all been described in cancer. Arterial tromboembolism is much less common than venous thrombosis in cancer, although it can be secondary to nonbacterial thrombotic endocarditis. However, there is evidence of an association between arterial disease and the disturbances in homeostasis, thrombosis, and vascular function that are also present in cancer [1]. Spontaneous arterial thrombosis is a rare presentation of TS. Rigdon et al. [5] reported three patients who were acute arterial thrombosis on extremities without significant atherosclerosis on arm or legs, but who were subsequently discovered to have occult malignancy. But stroke as a fist symptom of occult cancer is very rare as in our patient [6]. Our patient had no any marker for a cancer on his history and physical examination unless the acute ischemic stroke. Due to multiple ischemic lesions in different ages on his brain CT was extensively investigated to find an etiology but we did not find it. Only his homosistein level was high. Because relation between homosistein level and stroke is uncertain, possibility of the cause of the stroke in the patient was less likely [7]. When he was being thought discharge, we faced a thrombophilic phenomenon on his left upper and lower extremities. In that time, a hypercoagulobility status in systemic arterial and venous bed of the patient were considered. This subject made us suspect an occult cancer under all these things.

Thrombosis is the second most common cause of death among patients with cancer. While it is well established that cancer increases the risk of thromboembolism, the mechanisms have not been defined conclusively. Multiple factors are responsible for the hypercoagulable state of malignancy, including disorders of both the tumors and host. There are some hypotheses about genetic pathways within tumor cells that might trigger these thrombotic phenomena. Tumours can secrete procoagulant factors and pro-inflamatory cytokines. Tumour-derived tissue-factor-bearing micro particles have been described. These microparticles are more abundant in pa- tients with cancer with venous thromboembolism than in patients with cancer without venous thromboembolism. Patients with cancer also frequently host procoagulant circumstances such as immobility, dehydration, compromised venous blood flow, surgery, and certain medical treatments $[3,8,9]$.

As a conclusion, acute, sub-acute or even chronic multiple cerebral infarction may be the first manifestation of an undiagnosed occult cancer. If there is multiple infarctions in a brain and/or clinical evidence of multiple progressive hypercoagulibilty situations in a patients with ischemic stroke of an unknown etiology should be investigated for an occult malignancy.

\section{REFERENCES}

[1] G. Y. Lip, B. S. Chin and A. D. Blann, "Cancer and the Prothrombotic State,” The Lancet Oncology, Vol. 3, No. 1, 2002, pp. 27-34. doi:10.1016/S1470-2045(01)00619-2

[2] A. A. Khorana and R. L. Fine, "Pancreatic Cancer and Thromboembolic Disease,” The Lancet Oncology, Vol. 5, No. 11, 2004, pp. 655-663. doi:10.1016/S1470-2045(04)01606-7

[3] A. Varki, “Trousseau's Syndrome: Multiple Definitions and Multiple Mechanisms,” Blood, Vol. 110, No. 6, 2007, pp. 1723-1729. doi:10.1182/blood-2006-10-053736

[4] L. R. Rogers, "Cerebrovascular Complications in Cancer Patients,” Neurologic Clinics, Vol. 21, No.1, 2003, pp. 167-192. doi:10.1016/S0733-8619(02)00066-X

[5] E. E. Rigdon, “Trousseau's Syndrome and Acute Arterial Thrombosis,” Journal of Cardiovascular Surgery, Vol. 8, No. 3, 2000, pp. 214-218.

[6] S. Giray, B. F. Sarıca, Z. Arlier and N. Bal, "Recurrent Ischemic Stroke as an Initial Manifestation of an Concealed Pancreatic Adenocarcinoma: Trousseau's Syndrome,” Chinese Medical Journal, Vol. 124, No. 4, 2011, pp. 637-640.

[7] R. Clarke, J. Halsey, D. Bennett and S. Lewington, "Homocysteine and Vascular Disease: Review of Published Results of the Homocysteine-Lowering Trials," Journal of Inherited Metabolic Disease, Vol. 34, No. 1, 2011, pp. 83-91. doi:10.1007/s10545-010-9235-y

[8] O. Y. Bang, J. M. Seok, S. G. Kim, J. M. Hong, H. Y. Kim, J. Lee, P. W. Chung, K. Y. Park, G. M. Kim, C. S. Chung and K. H. Lee, "Ischemic Stroke and Cancer: Stroke Severely Impacts Cancer Patients, While Cancer Increases the Number of Strokes," Journal of Clinical Neurology, Vol. 7, No. 2, 2011, pp. 53-59. doi:10.3988/jcn.2011.7.2.53

[9] P. J. Saylor and A. E. Fogerty, "Prostate-Cancer-Associated Hypercoagulability: Do We Need to Worry about Androgen Deprivation?” The Lancet Oncology, Vol. 11, No. 5, 2010, pp. 406-407. doi:10.1016/S1470-2045(10)70063-2 